\title{
Características de la movilidad intrametropolitana en el estado de São Paulo, Brasil, 1970-1980
}

\section{José Marcos Pinto da Cunha*}

La región metropolitana conocida como "Grande São Paulo" estaba compuesta en 1980 por 37 municipios, y representaba cerca de $11 \%$ de la población brasileña y $51 \%$ del estado de São Paulo. Su rápido crecimiento en las últimas décadas estuvo íntimamente ligado a la cuestión migratoria.

Este gran crecimiento y la concentración demográfica trajeron aparejada una profunda modificación en la distribución interna de la población en ese espacio. En este contexto, juegan un papel importante los movimientos migratorios intrametropolitanos que se traducen en la transferencia de miles de personas, sobre todo desde el centro (la capital), hacia los municipios de su alrededor, y en localidades cada vez más lejanas.

El presente estudio busca, a partir del censo de 1980, brindar un cuadro general de este tipo de migración, utilizando la información acerca del municipio de residencia anterior, por primera vez en los censos brasileños, que permite establecer los flujos migratorios intermunicipales internos; aspectos relativos a volúmenes, dirección y sentido de los movimientos, así como algunas características de los agentes involucrados son presentados.

Del análisis empírico se pueden deducir por lo menos dos grandes conjuntos de motivaciones (o constreñimiento) para el cambio de municipio: aquellas ligadas a las formas de utilización del suelo urbano, en especial respecto al acceso a vivienda, y aquellas debidas a la reorganización de la actividad económica, y, por ende, del mercado de trabajo en el espacio metropolitano.

\section{Introducción}

La región metropolitana del estado de São Paulo (la Grande São Paulo), formada por 37 municipios (menor división administrativa), localizada al sureste del estado en un área de $8053 \mathrm{~km}^{2}$, y con una población de $\mathbf{1 2 . 5}$ millones de personas, representaba en 1980 cerca de $11 \%$ de la población de Brasil y más de la mitad del estado.

Además, en esta región se encuentra la capital del estado (municipio de São Paulo), así como el mayor centro industrial y de servicios del país, lo que lleva a que históricamente haya sido un gran polo de atracción de los movimientos migratorios nacionales

\footnotetext{
* Núcleo de Estudos de Populaçāo, Universidad Estadual de Campinas, Brasil.
} 
intensos desde las décadas de los cuarenta y los cincuenta. Como reflejo de este atractivo fueron los saldos migratorios registrados que llegaron a más de 4.2 millones de personas entre 1960 y 1980.

En 1980,67\% de la población metropolitana era no-natural del municipio donde vivia, valor que aumentó a más de $77 \%$ en muchos de los municipios, lo que muestra que la región está básicamente formada por migrantes y por sus descendientes.

En este contexto, y en un estado del conocimiento donde mucho se sabe en términos migratorios sobre la Grande São Paulo y su relación con otras áreas dentro y fuera del estado (Cunha, 1986; Goldani, 1983, entre otros), surge un tema aún poco explorado, sobre todo en términos demográficos, y que presenta varias implicaciones para la dinámica demográfica local: la migración intrametropolitana.

Este fenómeno, por su magnitud, es responsable del crecimiento sin precedentes de varios municipios metropolitanos. Asimismo es un elemento fundamental para la comprensión de procesos como la desconcentración poblacional, la "periferización", el surgimiento de áreas dormitorios, la migración "pendular", etcétera.

La migración intrametropolitana; aspectos cuantitativos y cualitativos

\section{El fenómeno en cifras}

Es significativo el hecho de que en uno de los mayores centros de atracción migratoria del país, la Grande São Paulo, cerca de $28 \%$ de todos los no-nativos de los municipios con menos de 10 años de residencia (a partir de ahora llamados inmigrantes) presenten como último origen algún área de la misma región. Son, por lo tanto, más de 920 mil personas envueltas en los intercambios internos de población ocurridos en la década de los setenta. Además, aunque no se disponga de información sobre la década anterior, las evidencias indican que los años setenta fueron marcados por una mayor intensidad en el desarrollo de este fenómeno.

La importancia de este tipo de migración en la dinámica demográfica regional queda clara cuando se observa que en muchos de los municipios metropolitanos más de una cuarta parte de su población, en 1980, estaba compuesta por migrantes intrametropolitanos de la década anterior. En algunos casos particulares esta cifra llega a $43 \%$, como es el caso de Embú, $36 \%$ en Carapicuíba y $35 \%$ en Taboao da Serra, todas áreas próximas a la capital que, 
a su vez, absorben gran parte de la fuerza de trabajo que allí vive.

La gran mayoría de los municipios de la Grande São Paulo presentaron altas tasas de crecimiento demográfico en la década de los setenta. Algunas incluso tuvieron tasas superiores a $10 \%$ anual; si comparamos este crecimiento con el de la región como un todo ( $4.46 \%$ a.a.), esto se explica en buena medida por los movimientos migratorios internos.

De hecho, los datos muestran que en casi la mitad de los municipios metropolitanos, más de $30 \%$ del crecimiento demográfico se debió al saldo neto migratorio, es decir, inmigración menos emigración de los intercambios poblacionales internos. Incluso en algunos casos, este porcentaje alcanzó valores mucho mayores, como en Franco da Rocha (60\%), Francisco Morato (51\%), Taboao da Serra (49\%), Itapecerica da Serra (49\%), Embú (48\%), Ferraz de Vasconcelos (43\%), etc. Todas estas áreas son consideradas como dormitorios.

Íntimamente relacionado con lo anterior está el proceso de redistribución espacial de la población en la Grande São Paulo que alcanzó una intensidad considerable en las últimas décadas. Assi, por ejemplo, mientras la capital representaba en 1960 , casi $78 \%$ de la población metropolitana, en 1980 este porcentaje cayó a $67.5 \%$. En este contexto, hubo una transformación radical en la configuración de la región en términos del tamaño de las poblaciones municipales. Mientras en $1960,73 \%$ de los municipios presentaban una población inferior a 20 mil habitantes, en 1980 esta cifra bajó a $\mathbf{2 0 \%}$, en cambio creció el número de áreas con localidades de más población como: 20 a 50 mil (de 3 a 8 municipios), 50 a 100 mil (de 2 a 11) y 100 mil o más (de 5 a 11).

De la misma forma, la gran intensidad de la migración intrametropolitana provocó la intensificación de otro fenómeno que en Brasil se acordó en llamar migración "pendular", es decir, el desplazamiento diario de personas para otros municipios, en función especialmente de una actividad laboral. Del total de los migrantes internos económicamente activos de la década de los setenta, $49 \%$ emprendía este tipo de movimiento, lo que arroja una cifra de cerca de $\mathbf{2 0 0}$ mil individuos, que se suman a otras miles de personas que tienen que dejar su municipio durante el día para ejercer sus actividades en otra localidad.

En cuanto a los volúmenes, direcciones y sentidos de los flujos migratorios, lo que se observa es que a pesar de las 1332 posibilidades (tomando en consideración los 37 municipios), la gran mayoría son numéricamente irrelevantes. De hecho, más de dos terceras partes de todos los desplazamientos internos pertenecen apenas a 23 flujos, o sea, menos de $2 \%$ del total. 
En relación con los orígenes de los movimientos, se observa que 31 de los municipios metropolitanos (84\%) tienen a São Paulo (la capital) como el área principal de salida de sus inmigrantes, éste es uno de los aspectos que mejor caracterizan los movimientos internos en la Grande São Paulo. Este hecho, aparentemente contradictorio con la condición del municipio de São Paulo (con 8.4 millones de habitantes) de gran polo de atracción de los migrantes interestatales e interregionales, refleja el desplazamiento de la población en dirección a los municipios vecinos.

Por otro lado, en términos de los destinos, se observa una mayor diversidad de situaciones destacándose tanto municipios industrializados como Santo André, São Bernardo do Campo, São Caetano do Sul, Guarulhos e Osasco, así como áreas con un menor desarrollo relativo como Mogi das Cruzes, Suzano, Ribeirao Pires, Mauá, y aquellas netamente dormitorios o agrícolas como Baruerí, Carapicuiba, Ferraz de Vasconcelos, Embú, Taboao da Serra, Itapecerica da Serra, Francisco Morato, entre otros.

El mapa 1, con los flujos migratorios numéricamente más importantes, permite, de forma resumida, una visualización de las principales tendencias de los movimientos dentro de la Grande São Paulo. Un estudio más detallado sobre este tema se encuentra en Cunha (1987).

\section{Especificaciones según el origen y destino}

La hipótesis que se pretende poner a prueba con el análisis cualitativo de los flujos migratorios se refiere al hecho de que los movimientos intrametropolitanos responden a un conjunto complejo y variable de condicionantes y, por lo tanto, varias de las características de los migrantes tenderían a ser distintas según se trate de la migración en una u otra dirección. En el presente estudio, la observación de estas supuestas diferencias será muy útil para la percepción de los varios condicionantes relativos a este tipo de migración.

Aun reconociendo la complejidad y diversidad de situaciones dentro de la Grande São Paulo, es posible identificar por lo menos dos grandes procesos a los que responden las migraciones internas en esta región: el que se suele llamar de "periferización" y la redistribución espacial de la actividad económica.

Respecto al primer proceso es necesario aclarar inicialmente que el término periferización puede ser entendido bajo varias ópticas. En este estudio se tomará el sentido sociológico, es decir, la periferización social que, al contrario de su acepción geográfica, 


\section{MAPA 1}

Corrientes migratorias numéricamente más importantes según el volumen de migrantes. Región Grande São Paulo, 1970-1980

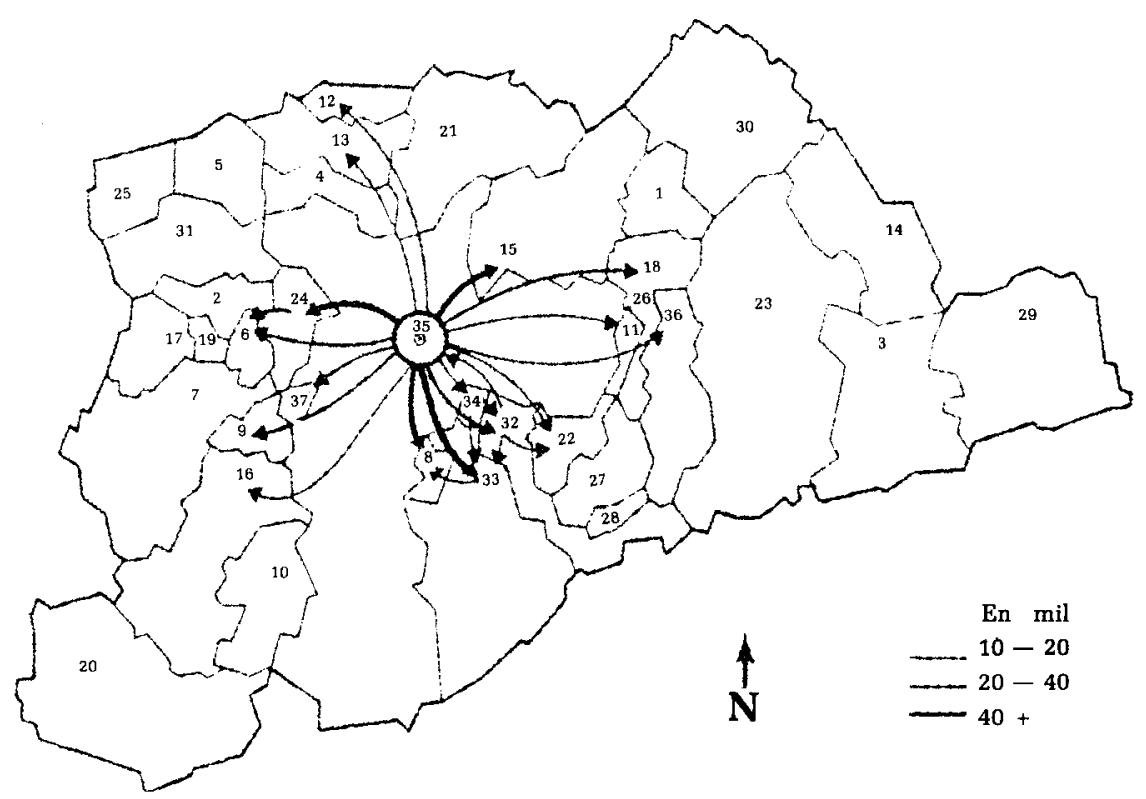

GRANDE SÃO PAULO
1. Arujá
2. Barueri
3. Biritiba-Mirim
4. Caleiras
5. Cajamar
6. Carapicuíba
7. Cotia
8. Diadema
9. Embu
10. Embu-Guaçu
11. Ferraz de Vasconcelos
12. Francisco Morato
13. Franco da Rocha

14. Guararema
15. Guarulhos
16. Itapecerica da Serra
17. Itapevi
18. Itaquaquecetuba
19. Jandira
20. Juquitiba
21. Mairiporá
22. Mauá
23. Mogi das Cruzes
24. Osasco
25. Pirapora do Bom Jesus

26.Poā

27. Ribeirāo Pires

28. Rio Grande da Serra

29.Salesōpolis

30.Santa Isabel

31.Santana do Parnaíba

32.Santo André

33.Sāo Bernardo do Campo

34.São Caetano do Sul

35.Sāo Paulo

36.Suzano

37. Taboāo da Serra

Fuente: Fundação Instituto Brasileiro de Geografia e Estatística, IBGE, Censo Demográfico de São Paulo, 1980. Rio de Janeiro, 1982 (tabulación especial). 
no depende necesariamente de una localización espacial. Esta noción, que se refiere a los lugares en donde la fuerza de trabajo se reproduce en malas condiciones generales de vida, fue utilizada, en la década de los setenta, en otros estudios sobre este fenómeno (Duarte et al., 1981; Montali, 1983; Bonduki y Rolnik, 1979, entre otros), en los cuales la migración intrametropolitana era incorporada como el factor demográfico propulsor de este proceso.

Aquí no se discute este hecho. Sin embargo, las evidencias empíricas dejan muy claro que la migración interna y la periferización no son un mismo proceso, y esta última apenas es una de las consecuencias posibles de la primera. En este sentido, la reorganización espacial de la actividad productiva también ha sido, seguramente, uno de los factores más importantes que contribuyeron en la intensa movilización interna en la Grande São Paulo durante los años setenta.

Así es que del volumen migratorio representado por los 23 flujos que constan en el mapa 1 (cerca de 620 mil personas), más de $50 \%$ corresponde a aquellos cuyo lugar de destino fueron los municipios más desarrollados e industrializados de la región como: São Bernardo do Campo, Santo André, São Caetano do Sul (estos tres denominados el ABC paulista), Guarulhos y Osasco. No hay duda, por lo tanto, de que muchos de los desplazamientos se justifican por razones ligadas a la posibilidad de la inserción productiva de los migrantes en nuevos y más dinámicos mercados de trabajo, que fueron surgiendo en el área metropolitana.

El análisis cuidadoso del cuadro 1, que presenta las principales corrientes migratorias según el lugar de trabajo o estudio de los migrantes económicamente activos, contribuye para afianzar la hipótesis de la existencia de los dos procesos anteriormente nombrados. Al conocer la importancia absoluta y relativa del volumen de personas que, a pesar de haber migrado para un determinado municipio, no ejercen allí sus actividades (migrantes "pendulares"), es posible inferir en qué medida estos desplazamientos estuvieron motivados por la búsqueda, por ejemplo, de locales de vivienda más baratos, o mejores oportunidades laborales.

De hecho, se observa una gran diferenciación entre los flujos migratorios presentados. En aquellos cuyos destinos son municipios industriales (ABC paulista, Guarulhos, etc.), el porcentaje de la PEA que trabaja/estudia fuera fue, en general, inferior a $50 \%$, mientras que en los flujos en dirección a municipios dormitorios y agrícolas esta cifra alcanzó a superar $70 \%$, como en Carapicuíba, donde $80 \%$ de los migrantes intrametropolitanos de la década, provenientes de São Paulo u Osasco, eran pendulares.

Otro elemento a destacar se refiere al porcentaje de los mi- 


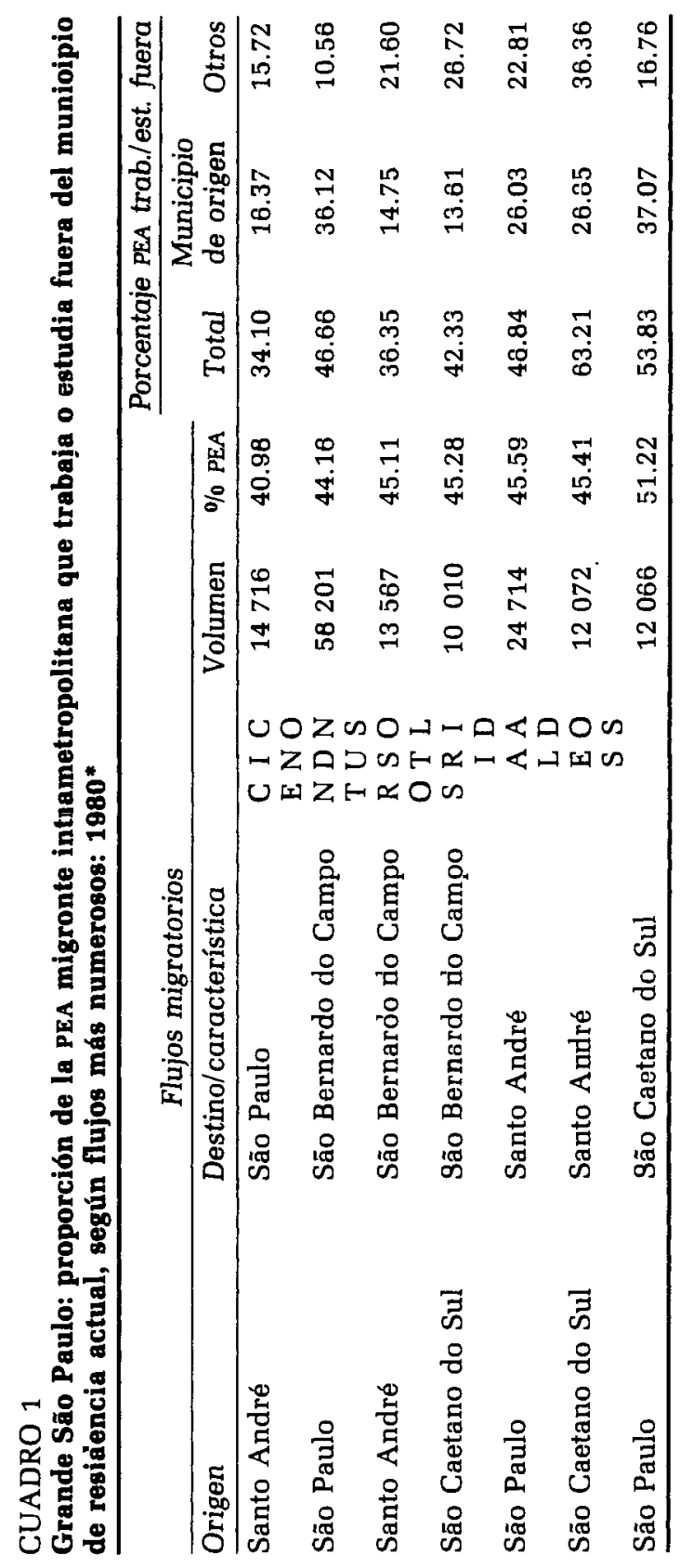




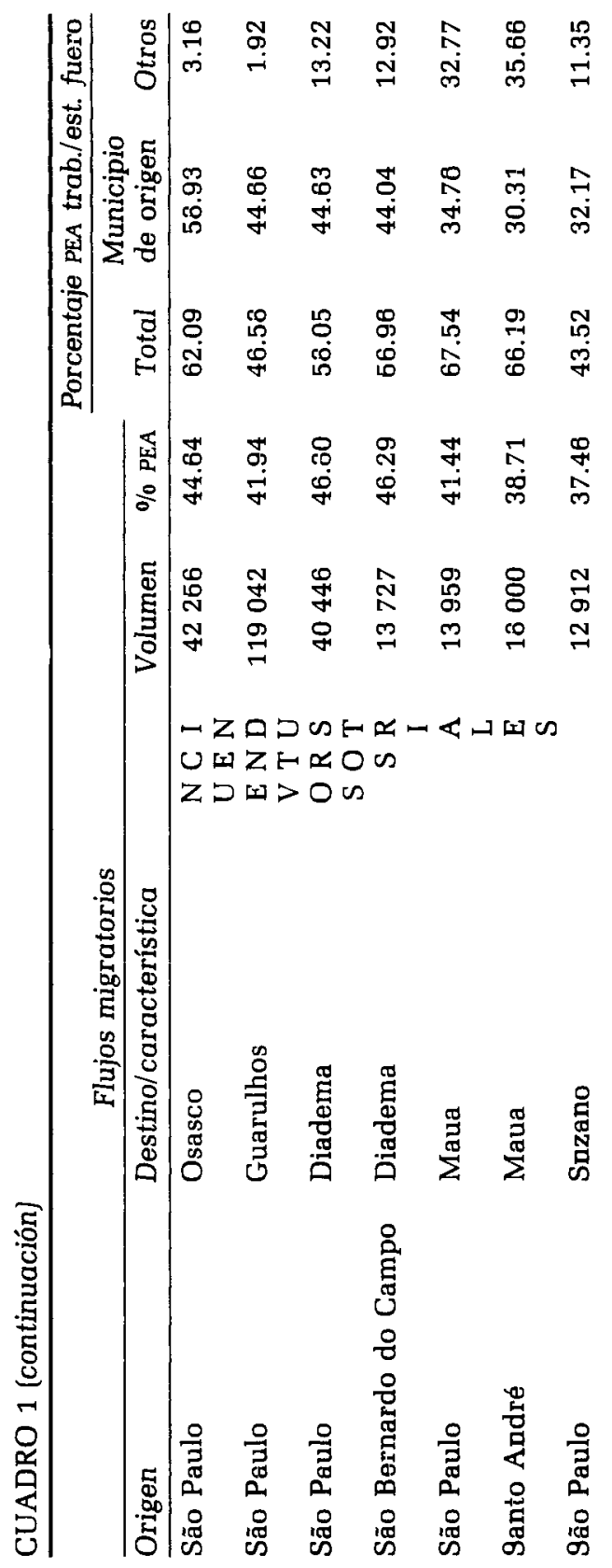




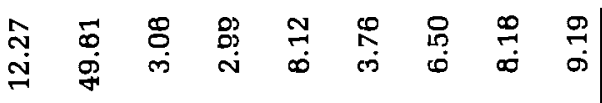

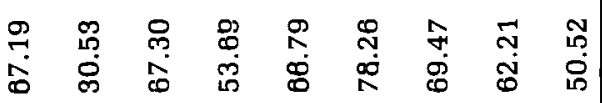

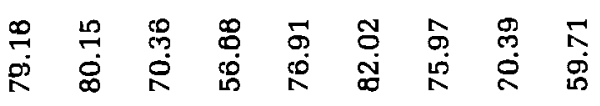

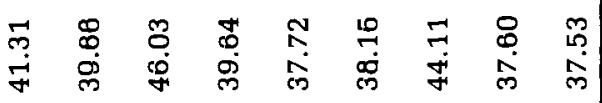

$$
\begin{aligned}
& \text { ‡ ‡ } \\
& \text { ल ब }
\end{aligned}
$$

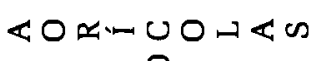

$$
\begin{aligned}
& \text { ด }
\end{aligned}
$$

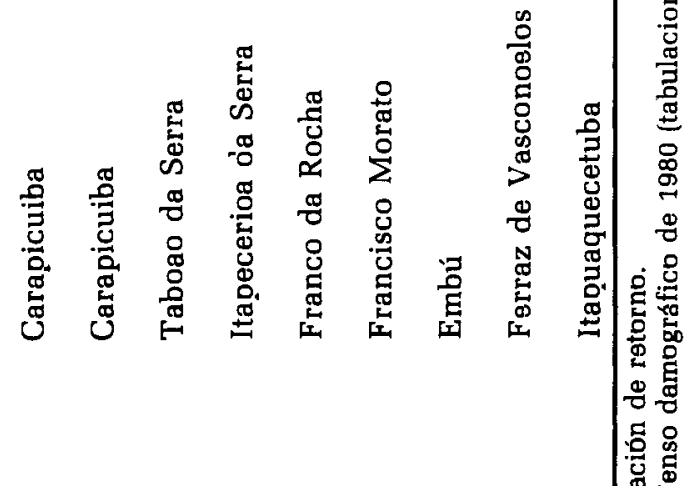


grantes que trabajan o estudian en el municipio de origen de los respectivos flujos. De esta manera se constata que son en aquellas áreas menos desarrolladas en donde estos valores son más elevados, en general superiores a $60 \%$, lo que sugiere que en estos casos el movimiento migratorio no implica para la mayoría de la PEA un cambio respecto del mercado de trabajo. No se observa lo mismo en municipios industriales, en donde es pequeño el porcentaje de migrantes que siguen trabajando o estudiando en el lugar de la última residencia.

Frente a estas evidencias se debe suponer que los elementos condicionantes del conjunto de flujos direccionados para los $\mathrm{mu}$ nicipios más desarrollados no son los mismos -aunque pueden presentar semejanzas en algunos aspectos- que aquellos que influyeron en las áreas cuyo desarrollo relativo es menor.

Es más, puede decirse que el proceso de periferización trae aparejado la formación y el crecimiento de los llamados municipios dormitorios, cuya función sería exclusivamente la de abrigar la fuerza de trabajo que en gran proporción se sirve de los mayores mercados para incorporarse a la actividad económica. Por otro lado, la existencia de otros centros urbanos industriales abre nuevas alternativas en el cuadro metropolitano, lo que implica nuevos desplazamientos de la mano de obra (con sus familias), sobre todo desde el municipio de São Paulo, en este caso básicamente por motivos laborales.

Del mismo modo, en términos de las categorías socio-ocupacionales, se percibe una mayor participación en la PEA "empleados no-manuales" en los flujos dirigidos a zonas más desarrolladas, mientras que el porcentaje es menor para empleados manuales en la industria tradicional (donde poca tecnología es utilizada): comercio, servicios y transportes, que tienden a tener mayor representación entre los migrantes cuyo destino son los municipios de menor desarrollo relativo. A pesar de no haber presentado en el cuadro 2 todas las posibles categorías socio-ocupacionales, se puede percibir una importante diferenciación en términos de especialización y situación económica entre los componentes de los flujos migratorios.

Se debe agregar también que este comportamiento se muestra coherente con el tipo de demanda que se supone pueda generar el parque industrial de municipios como São Bernardo do Campo, Santo André, São Caetano do Sul, Guarulhos, etc., en comparación con el mercado en este mismo sector del municipio de São Paulo - principal área de origen de los movimientos internosque se encuentra más estancado y saturado.

Respecto a los ingresos, la situación no se modifica, lo que 


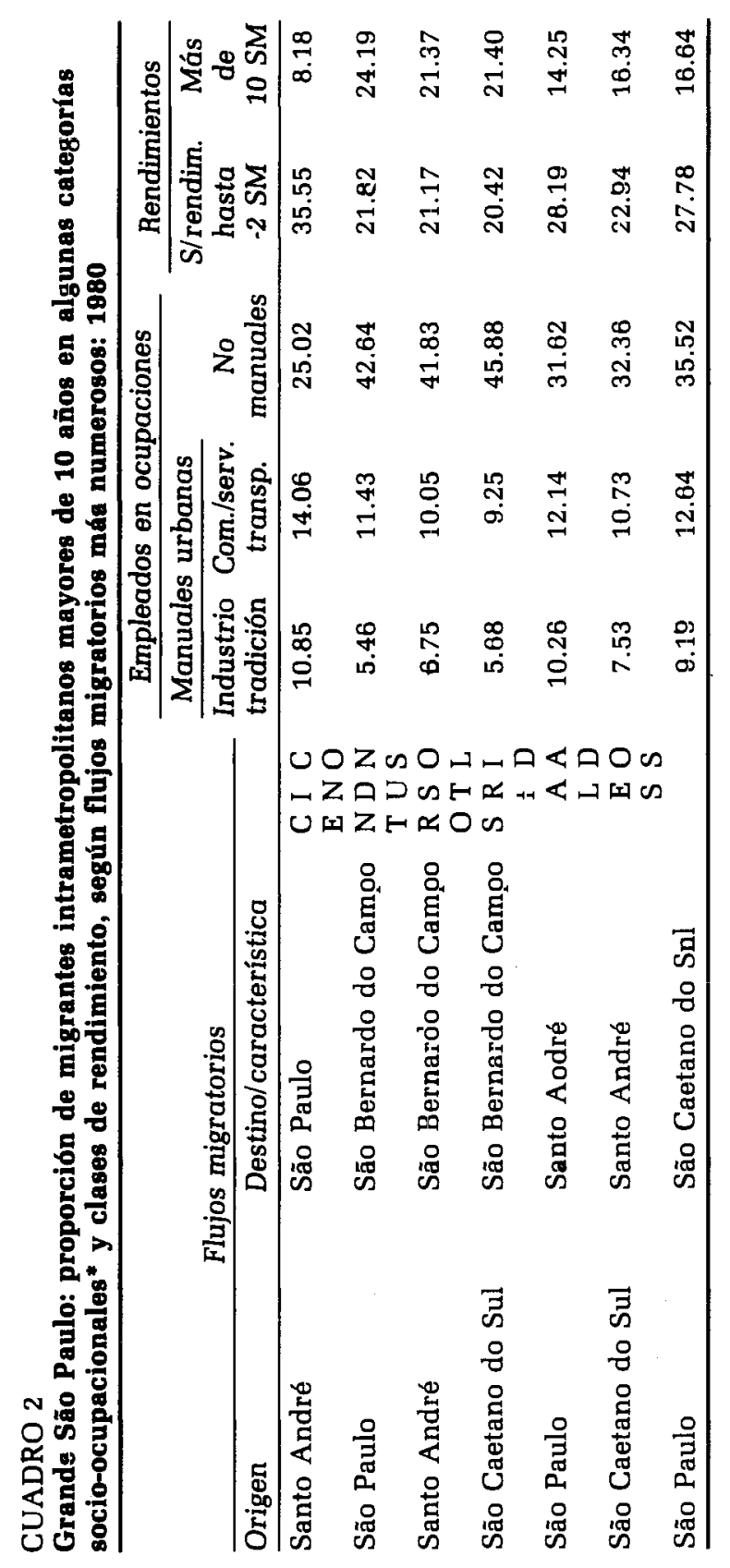




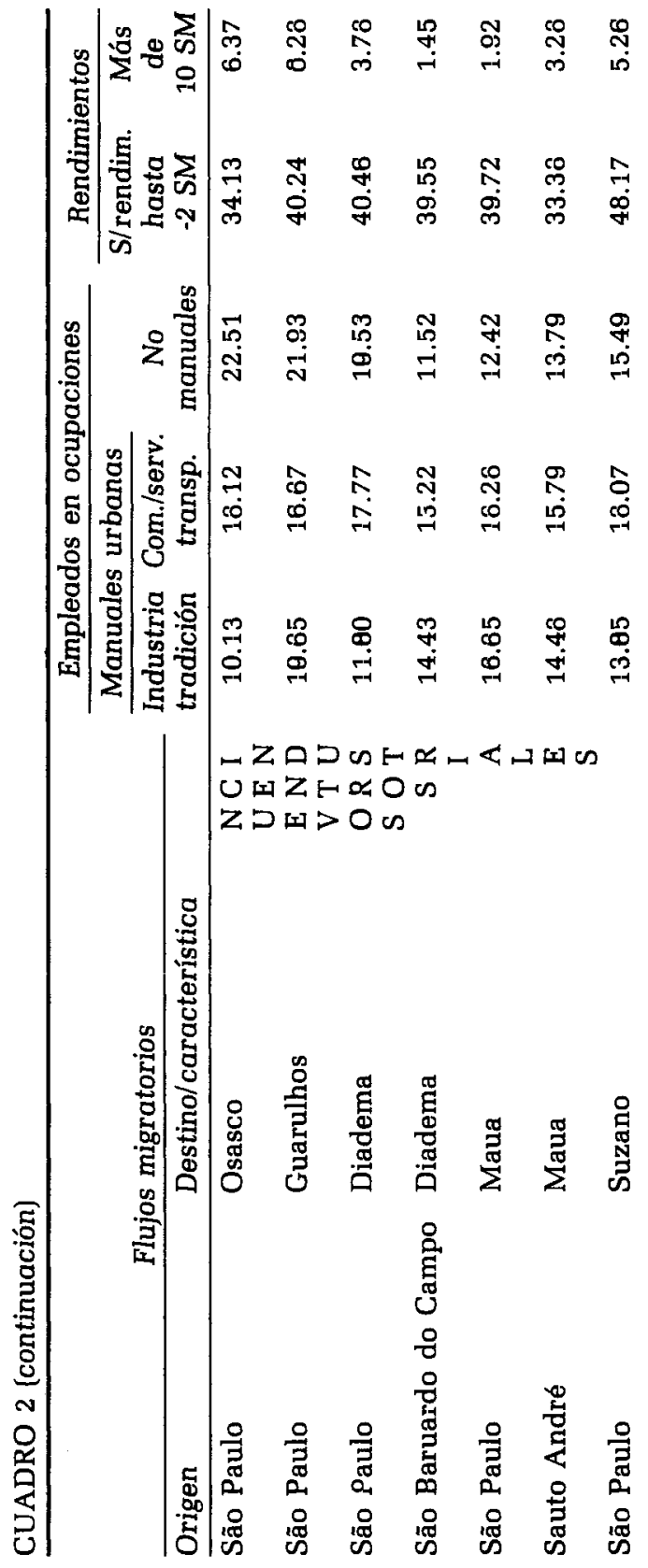




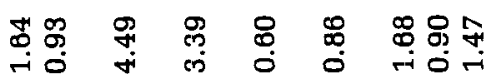

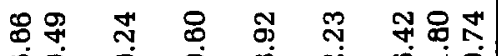

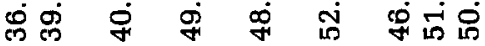

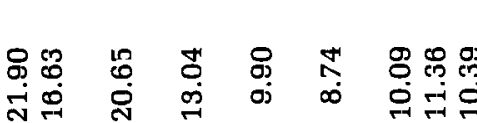

$$
\begin{aligned}
& \text { ำ }
\end{aligned}
$$

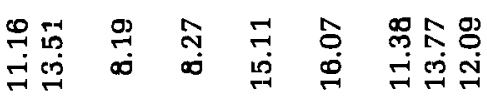

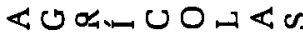

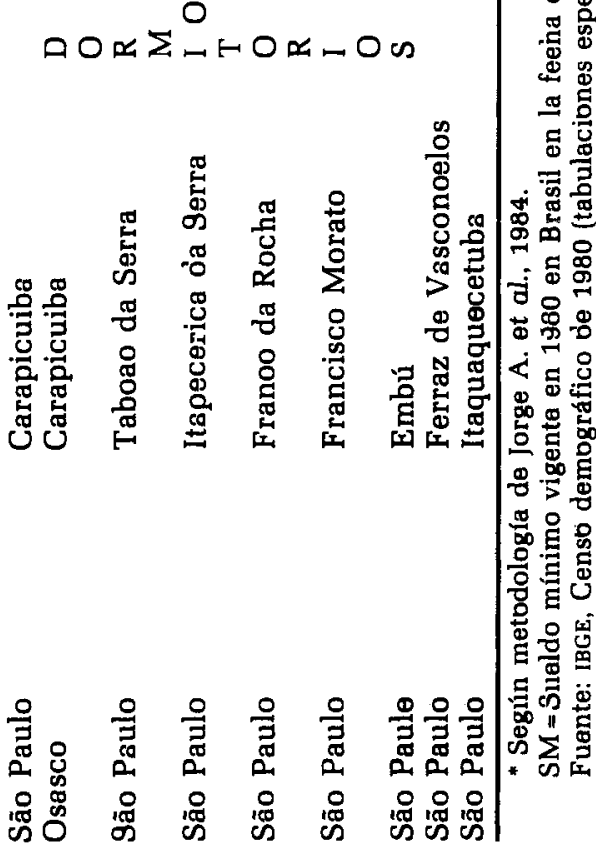


vale decir que también en este caso los migrantes con mejores niveles de ingresos son aquellos cuyo destino son las áreas industriales. De hecho, mientras que la proporción de personas mayores de 10 años sin ingresos o con menos de 2 salarios mínimos (equivalente a cerca de 73 dólares en 1980) llega a cerca de $50 \%$ en las corrientes dirigidas hacia municipios dormitorios como Embú, Ferraz de Vasconcelos, Francisco Morato, etc., esta cifra no rebasa $30 \%$ en las regiones antes citadas. En el otro extremo, por supuesto, la situación se invierte y las desigualdades se acentúan aún más entre los flujos, llegando a situaciones como las registradas para el flujo São Paulo-São Bernardo do Campo donde $24.1 \%$ de las personas recibían 10 o más salarios mínimos y, por ejemplo, São Paulo-Ferraz de Vasconcelos, donde éstas representaban apenas 0.9 por ciento.

Así, es posible identificar una relación consistente entre las condiciones económicas y sociales de los migrantes y sus trayectorias. Esto sugiere que los movimientos intrametropolitanos no ocurren aleatoriamente en el espacio, sino que poseen una cierta lógica que implica selectividad específica para las distintas direcciones de los flujos migratorios.

Por supuesto que un determinado flujo migratorio puede constituirse en acción conjunta de los dos procesos aquí mencionados y, por lo tanto, la dicotomización adoptada limitaría la visualización del complejo cuadro de condicionantes del fenómeno. Se supone que, de hecho, esto ocurre con mayor intensidad en las corrientes dirigidas hacia municipios como Guarulhos, Osasco, Diadema, o bien Mauá, que antes de consolidarse como zonas industriales se configuraban como áreas dormitorios de la capital y el ABC paulista. Sin embargo, no se puede negar que existe en la mayoría de los principales flujos intrametropolitanos una cierta hegemonía de un proceso respecto del otro.

De todas formas, el presente análisis definitivamente descalifica cualquier tentativa de asociar migración intrametropolitana y periferización, que parta de considerar que la primera pudiese ser entendida solamente en el contexto de la última.

\section{Conclusiones}

Aunque de forma sucinta, el presente trabajo buscó brindar un panorama bastante general de lo que fue el fenómeno de la migración intrametropolitana en el estado de São Paulo. Los resultados, además de of recer algunas de las principales características en términos de su importancia numérica y sus consecuencias, permi- 
tieron sugerir que este tipo de movimiento poblacional estuvo ligado al desdoblamiento de dos procesos: la periferización, consecuencia de los problemas urbanos ligados a la utilización y valorización del suelo y la redistribución espacial de la actividad productiva dentro de la región.

En este contexto surgen por lo menos dos tipos de flujos migratorios: aquellos dirigidos hacia municipios con clara función de dormitorio, para los cuales se dirigen los migrantes básicamente en búsqueda de mayor accesibilidad al espacio, o más específicamente a la vivienda, y los dirigidos a áreas donde el desarrollo urbano-industrial relativo es mayor, lo que significa para ellos nuevas y (o) mejores alternativas económicas. También es importante resaltar que los elementos nombrados anteriormente pierden mucho de su significado si no son contextualizados en un cuadro de problemas urbanos, valorización inmobiliaria, saturación del mercado de trabajo, desplazamiento de la actividad industrial y cambio de función económica que viene presentándose en el municipio de São Paulo.

Finalmente, vale la pena reforzar la convicción de que el fenómeno de la migración intrametropolitana responde a un conjunto de procesos mucho más complejos que el adoptado aquí, fundado en la dicotomía periferización y redistribución espacial de la actividad económica. Por este motivo, se considera que la contribución del presente estudio es solamente un primer paso en dirección a lograr un conocimiento más amplio del fenómeno.

\section{Bibliografía}

Altman, A.M.G. (1984), "Grande São Paulo", Serie Análise Demográfica Regionol, São Paulo, Fundação SEADE.

Blay, E.A. (coord.) (1978), A luta pelo espaço, texto de sociología urbana, Petrópolis, Editora Voses.

Bonduki, N.G. y R. Rolnik (1979), "Periferias: ocupação do espaço e reprodução da forma de traballıo", en Cadernos de estudo e pesquisa 2, São Paulo, PRODEUR/FAU-USP.

Camarco, C.P.C. et ai. (1975), São Paulo-1975. Crescimento e pobreza, São Paulo, Ed. Loyola.

Cunha, J.M.P. (1986), Os deslocomentos populacionais na década de 70 na Grande São Paulo: un enfoque das correntes migratórias, Aguas de São Pedro, S.P., ABEP, Anais do V Encontro Nacional.

(1988), "A migração nas Regioes Administrativas do estado de São Paulo, segundo o censo de 1980", Revista Brasileira de Estudos de População, vol. 4, núm. 2, São Paulo, ABEP.

Duarte, J. C. (coord.) (1981), Migrações intrametropolitanas, reprodução da 
força de trabalho e formação da periferia de São Paulo, PRODEUR/ FAU-USP (mimeo.).

Jorge $A$. et al. (1984), Categorias sácio-ocupacionais: uma perspectiva para análise da força de trabalho e distribuição de rendimentos no Brasil, São Paulo, ABEP, IV Encontro Nacional.

Kowarick, L. (1979), A espoliação urbana, Rio de Janeiro, Paz e Terra.

Montali, L. (1983), Periferia: o crescimento da pobreza, São Paulo, FAU/USP (mimeo.).

Montali, L. et al. (1981), Recursos migratórios: constituição das formas de reprodução do trabalho urbano, São Paulo, PRODEUR-FAU/USP, relatorio de pesquisa.

Patarra, N.L. y L.M. Bogus (1980), "Rercusos migratórios e ocupação do espaço urbano: um estudo de caso", en ABEP, Anais do II encontro nacional, voi. 2, Aguas de São Pedro, São Paulo.

Singer, P.I. (1968), Desenvolvimento económico e evolução urbana, São Paulo, Cia. Nacional/EDUSP.

(1978), "Uso do solo na economia capitalista", en Revista Chao, núm. 3, Río de Janeiro, 1/EDUSP. 